\title{
Conquer fear: protocol of a randomised controlled trial of a psychological intervention to reduce fear of cancer recurrence
}

\author{
Phyllis N Butow ${ }^{1 *}$, Melanie L Bell ${ }^{1}$, Allan B Smith¹, Joanna E Fardell ${ }^{1}$, Belinda Thewes ${ }^{1}$, Jane Turner², \\ Jemma Gilchrist ${ }^{3}$, Jane Beith ${ }^{4}$, Afaf Girgis ${ }^{5}$, Louise Sharpe ${ }^{6}$, Sophy Shih', Cathrine Mihalopoulos ${ }^{7}$ \\ and members of the Conquer Fear Authorship Group
}

\begin{abstract}
Background: Up to $70 \%$ of cancer survivors report clinically significant levels of fear of cancer recurrence (FCR). Despite the known negative impact of FCR on psychological wellbeing and quality of life, little research has investigated interventions for high FCR. Our team has developed and piloted a novel intervention (Conquer Fear) based on the Self-Regulatory Executive Function Model and Relational Frame Theory and is evaluating Conquer Fear in a randomised controlled trial (RCT). We aim to compare the efficacy and cost-efficacy of the Conquer Fear Intervention and relaxation training in reducing the impact of FCR.

Methods/design: This study is a multi-centre RCT with 260 participants randomised either to the Conquer Fear Intervention or relaxation training. Both interventions will be delivered in five sessions over 10 weeks by trained psychologists, psychiatrists and social workers with five or more years experience in oncology. Conquer Fear sessions use attentional training, detached mindfulness, meta-cognitive therapy, values clarification and psycho-education to help patients change the way they regulate and respond to thoughts about cancer recurrence. Relaxation training includes training in progressive and passive muscle relaxation, meditative relaxation, visualisation and "quick relaxation" techniques. Relaxation was chosen to control for therapist time and attention and has good face-validity as an intervention. The primary outcome is fear of cancer recurrence. Secondary outcomes include distress, quality of life, unmet needs, and health care utilisation. Participants complete questionnaires prior to starting the intervention, immediately after completing the intervention, 3 and 6 months later. Eligible participants are early-stage breast or colorectal cancer survivors who have completed hospital-based treatment between 2 months and 5 years prior to study entry and report a score in the clinical range on the Fear of Cancer Recurrence Inventory. The biostatistician is blinded to group allocation and participants are blinded to which intervention is being evaluated. Randomisation is computer generated, stratified by therapist, and uses sequentially numbered sealed envelopes.
\end{abstract}

Discussion: If successful, the study will provide an evidence-based intervention to reduce psychological morbidity in cancer survivors, and reduce overall health care costs due to more appropriate use of follow-up care and other health services in this very large population.

Trial registration: Australian New Zealand Clinical Trials Registry ACTRN12612000404820

Keywords: Fear of cancer recurrence, Cancer, Oncology, RCT, S-REF model, Intervention, Metacognition, Detached mindfulness

\footnotetext{
* Correspondence: phyllis.butow@sydney.edu.au

${ }^{1}$ Psycho-Oncology Co-operative Research Group (PoCoG), School of

Psychology, The University of Sydney, Sydney, NSW 2006, Australia

Full list of author information is available at the end of the article
}

\section{Biomed Central}

(c) 2013 Butow et al.; licensee BioMed Central Ltd. This is an Open Access article distributed under the terms of the Creative Commons Attribution License (http://creativecommons.org/licenses/by/2.0), which permits unrestricted use, distribution, and reproduction in any medium, provided the original work is properly cited. 


\section{Background}

Improved medical treatments have led to higher survival rates for many cancers. According to recent estimates, about $2 \%$ of the Australian population is currently living with a diagnosis of a malignant cancer [1]. In 2004 there were approximately 655,000 Australian cancer survivors diagnosed with cancer during the previous 23 years [2]. In 2005, the US Institute of Medicine released a landmark report From Cancer Patient to Cancer Survivor: Lost in Transition [3]. The report was critical of the paucity of intervention research to address the psychosocial consequences of cancer and its treatments, and stated that 'addressing survivors' unmet needs and providing greater clarity around follow-up is likely to lead to significant efficiencies in health care delivery and potential cost savings." [3]. One of the most prevalent unmet needs in survivors is for help with fear of cancer recurrence (FCR), defined as the fear that cancer could return or progress in the same place or another part of the body [4]. Several large studies have found that 21-40\% of cancer survivors report a need for help dealing with FCR [5-7].

\section{Prevalence and trajectory of FCR}

High levels of FCR are very common, with $42-70 \%$ of survivors reporting clinically significant levels of FCR $[8,9]$. Of 1442 adult cancer survivors recruited through Australian cancer registries, $46 \%$ worried about the cancer returning or getting worse at 12 months postdiagnosis [10]. Longitudinal studies of cancer survivors show that FCR usually does not decrease over time [11-15] even when risk of recurrence is low. This finding is supported by two reviews including both crosssectional and longitudinal studies, which found little evidence for a relationship between time since diagnosis and FCR $[16,17]$. The enduring nature of FCR is exemplified by a study of long-term testicular cancer survivors (average time since diagnosis 11 years), which found that despite this population having a relatively low risk of relapse, $24 \%$ reported FCR bothered them 'quite a bit' and 7\% that it bothered them 'very much' [18].

\section{The importance of evidence-based treatments for FCR}

FCR has a functional impact on the lives of cancer survivors and their families. FCR is associated with poorer quality of life and emotional wellbeing; higher mental and physical fatigue; and higher depression and anxiety in cancer survivors [17]. In a recently published study of 218 younger patients with a history of early breast cancer, of the $70 \%$ reporting clinical levels of FCR, 25\% said FCR considerably impaired their mood and 19\% reported it considerably impaired their ability to make plans and set future goals [9]. Some studies have reported higher levels of FCR in caregivers than patients [19-21].
A survey of 76 psycho-oncology health professionals and 47 oncologists and nurses found that 30\% reported FCR was an issue for more than half their patients; $31 \%$ of doctors reported spending more than $25 \%$ of the time in follow-up consultations discussing FCR; $46 \%$ found dealing with FCR challenging; and $71 \%$ were interested in further training in how to manage FCR [22]. Despite evidence of the relationship of FCR with psychological morbidity and impaired quality of life, as well as a recognized need from health professionals, there is a lack of evidence-based treatments for FCR.

Additionally, a growing body of evidence suggests there may also be significant cost savings for the health system if FCR is effectively treated, because people with high FCR use more services or may avoid appropriate tests to identify recurrence in a timely fashion. The former group increase health care use by more frequently presenting for checks, whereas the latter group may present later with a recurrence and therefore require more invasive treatments than might otherwise have been required. Cancer patients with high FCR are: less satisfied with their care [23], more likely to refuse discharge from a cancer centre for follow-up [24,25], seek readmission to a specialised cancer centre [24] and use complementary and alternative medicines [9,26-28]. Higher FCR in young women previously diagnosed with early breast cancer was significantly associated with less frequent than recommended use of mammograms and ultrasounds and more frequent visits to general practioners [9]. Despite these findings, to date, a systematic analysis of the cost-implications of treating FCR has not been conducted.

\section{Previous interventions}

To date few studies have reported an intervention specifically designed to reduce FCR. The first to appear in the literature was a small pilot study of an intervention (6 face-to-face individual sessions with a specialist nurse) [29] based on the self-regulation / common sense model of illness [30,31]. To date no outcome results from this intervention have been published.

Three studies have reported interventions for concepts related but not identical to FCR: fear of cancer progression [32-34]. The first evaluated an uncertainty management intervention and the second an intervention to reduce fear of cancer progression (including patients with metastatic disease). However, neither had a clearly articulated theoretical model of these concepts or the interventions used to address them. Moreover, because FCR was not specifically targeted, it was not measured in either study, limiting their utility in this context. Both studies demonstrated an immediate impact of the intervention, but not long-term efficacy. Another nonrandomised study involving patients with mixed cancers 
and disease status has reported data on the efficacy of two interventions to reduce fear of disease progression. Herschbach et al. [34] assessed the impact of cognitive behaviour group therapy and a supportive-expressive group therapy compared to usual care. Patients were assessed prior to the intervention, at treatment completion, and at 3 and 12 months follow-up. Both intervention groups showed a significant reduction in FCR over time compared to the control group. Patients with metastases and cancer recurrence gained the most from the interventions, suggesting that the constructs targeted may have different meanings for disease-free individuals. Subsequent analyses showed that patients with higher education were more likely to have a reliable reduction in FCR [35].

Two further studies have evaluated group therapies designed to improve generic emotional outcomes for cancer survivors, where improvements in FCR were reported as a secondary outcome. The first, [36] involving 84 breast cancer survivors found significant reductions in FCR immediately following a 6-session Mindfulness-Based Stress Reduction group [37], but no long-term data have been published. The second [38] reported significant reductions in FCR immediately following a 12-week Emotion Regulation Group for breast cancer patients which included training in guided imagery, meditation, emotional expression, and exercises promoting control beliefs and benefit-finding. However, improvements in FCR were not sustained at 6 and 12 months post intervention.

In summary, very few studies have evaluated interventions designed specifically to reduce FCR in patients with mixed, early stage cancers, indicating a need for further large, randomised controlled trials of interventions to assist survivors in better managing their FCR.

\section{Aims}

The aims of this study are to evaluate in a randomised controlled trial (RCT), the efficacy and cost efficacy of a therapist-delivered intervention (Conquer Fear) in reducing the impact of FCR in disease-free breast and colorectal cancer survivors with clinical levels of FCR, compared to a relaxation training control intervention. Secondary aims are to evaluate patient satisfaction with the program and the relative cost-effectiveness of Conquer Fear and the relaxation interventions. Specific hypotheses are that:

1. Participants in the Conquer Fear intervention will have lower scores on the Fear of Cancer Recurrence Inventory of at least 14.5 (0.5 standard deviation) as compared to the attention control group (who receive relaxation therapy) at follow-up;

2. Participants in Conquer Fear will have less cancer specific distress, less anxiety and depression, better quality of life, fewer unmet needs, and less maladaptive metacognitions when compared to the control group;

3. Patients receiving Conquer Fear will find the therapy program useful for treating their FCR and be satisfied with the program; and

4. The Conquer Fear intervention will be cost-effective compared to the relaxation comparator intervention.

\section{Methods/design}

This multi-site, parallel randomised controlled trial is being led by the Psycho-Oncology Co-operative Research Group based at the University of Sydney, Australia during 2012-2014. This project was co-funded by beyondblue, National Breast Cancer Foundation and Cancer Australia, and registered with the Australian New Zealand Clinical Trials Registry with registration number ACTRN12612000404820. Ethics approval has been obtained from the Cancer Institute NSW Clinical Research Ethics Committee.

\section{Participants \\ Therapists}

Twenty therapists from 15 sites have been recruited to deliver the study interventions via three Australian health professional networks: the Psycho-Oncology Co-operative Research Group (PoCoG), the Australian Psycho-Oncology Group and the Psychologists in Oncology Network. Therapists are eligible to participate in the study if they are registered psychologists, social workers or psychiatrists with a minimum of 5 years professional experience, and 2 years experience in oncology settings. Participating therapists are required to attend a one-day training course involving review of both intervention manuals and practice of the intervention techniques with feedback from senior psychologists/psychiatrists. The training course is based on a previous workshop for therapists who took part in the pilot study of the Conquer Fear intervention [22].

\section{Patients}

Patients are eligible to participate if they:

- have a confirmed past diagnosis of Stage 0-2 breast cancer or Dukes stage A-C colorectal cancer. These diagnostic groups were selected because they are prevalent; known to be affected by FCR $[10,39,40]$; have clearly defined staging to allow selection of patients with a good prognosis and in the case of colorectal cancer, include a mix of genders;

- are being treated with curative intent;

- have completed all hospital-based adjuvant treatments at least 2 months and not more than 5 years prior to study entry;

- are disease free; 
- have a score in the clinical range (13 or more) on the FCRI Severity Subscale possible range:0-36);

- are able to read and write English;

- are able to give informed consent.

Patients are ineligible if they:

- currently have severe major depression;

- currently are receiving psychological treatment from a therapist not involved in the study;

- currently have active psychotic illness or other psychiatric/cognitive condition.

Patients are recruited from Australian hospitals/cancer centres at which participating therapists are employed. The recruitment method varies between sites due to site-specific feasibility constraints. One recruitment method is for participating therapists to approach oncologists at their site to ask them to identify potentially eligible participants. Invitation letters printed on the sites' letterhead and signed by the treating oncologist are sent to a random selection of potentially eligible patients in small batches $(n=20)$ to avoid recruitment of more participants than can be managed by the therapist. A copy of the Severity Subscale of the Fear of Cancer Recurrence Inventory (FCRI) and a contact details form are included with the invitation letter for interested patients to send to the research team. A single reminder phone call is made to all patients invited to take part in the study if they do not respond to the invitation letter after two weeks. Invitation letters ask patients to: consider participation in the study; allow contact by the researchers; complete the Severity Subscale of the FCRI to determine their eligibility for study enrolment.

Alternatively, a study advertisement/flyer is displayed in clinic waiting rooms, or given to patients who express concern over their cancer coming back, by cancer nurse coordinators, therapists (i.e. psychologists or psychiatrists) or treating oncologists. The advertisement advises patients interested in taking part in the study to contact the study coordinators at the University of Sydney. These patients are then sent a copy of the Severity Subscale of the FCRI along with a reply-paid envelope to return to the research team.

Following receipt of the Severity Subscale of the FCRI the study team contacts the patients to confirm whether they are eligible, explains the study in further detail, answers any patient questions, obtains verbal consent, and mails the information sheet and consent form along with the baseline assessment to the patient.

\section{Randomisation}

Eligible patients who have given informed consent are randomly assigned to receive either the Conquer Fear or relaxation training intervention. The random allocation sequence is generated by a biostatistician blinded to the identity of participants and therapists, using computergenerated random numbers. Randomisation is stratified by therapist, with patients allocated in random blocks of 2 and 4 to enhance balance and reduce the likelihood of researchers or therapists guessing sequence generation. Each time an eligible patient gives informed consent to participate in the study a sequentially numbered envelope containing the patients' group allocation will be opened by a research co-ordinator who will then forward this information along with the patients contact details to the relevant participating therapist. The biostatistician is blinded to group allocation since the randomization list contains only A versus B and only the research coordinators know to which group these refer. The participants are also blinded in that they are not aware which is the primary intervention being evaluated.

\section{Interventions}

\section{The theoretical framework of conquer fear}

The Conquer Fear intervention is a theory-based intervention developed by a PoCoG-led group including international experts on FCR, psycho-oncology therapists and researchers, medical oncologists, an exercise physiologist, a breast physician and several consumers. The intervention is based on Meta-cognitive Therapy (MCT) [41], the treatment associated with the SelfRegulation of Executive Function (S-REF) Model of emotional disorders [42], together with components of Acceptance and Commitment Therapy [43] to address some of the existential issues related to experiencing a cancer diagnosis. Regarding the latter, it is well documented that cancer survivors commonly face a crisis of life direction: struggling with what life means to them now, what they want to value and see as important and how to lead a life that matters to them and those they love.

Importantly, the S-REF model of emotional disorders provides a mechanism by which high levels of FCR develop and are maintained. It posits that a cognitive appraisal system consisting of self-beliefs, knowledge and beliefs about the benefit and uncontrollability of worry, together with an autonomic appraisal system that evaluates the perceived level of threat associated with physical stimuli, are associated with FCR. Given cancer survivors face a real risk of cancer recurrence, rather than directly challenging the fears associated with a possible recurrence, MCT is well suited to cancer survivors as it works at the metacognitive level teaching clients more effective ways to respond to the presence of fears associated with a potential cancer recurrence. More detailed information regarding the novel theoretical formulation of FCR created by the research team will be published elsewhere. 
Table 1 Detailed content for the conquer fear intervention

\begin{tabular}{|c|c|c|}
\hline Session & Content & Home based practice \\
\hline \multirow[t]{4}{*}{1} & - FCR-specific assessment; & \multirow{3}{*}{$\begin{array}{l}\text { - Examine values identified in } \\
\text { session and devise relevant } \\
\text { goals (e.g. if identified value is } \\
\text { "being physically fit" devise } \\
\text { realistic ways to achieve this } \\
\text { and identify barriers to } \\
\text { achieving goal); }\end{array}$} \\
\hline & $\begin{array}{l}\text { - Model on which treatment is } \\
\text { based is explained; }\end{array}$ & \\
\hline & $\begin{array}{l}\text { - Discussion of existential } \\
\text { changes brought about by } \\
\text { cancer; }\end{array}$ & \\
\hline & - Values clarification exercise & $\begin{array}{l}\text { - Reflect on past experiences } \\
\text { and how these have shaped } \\
\text { response to cancer. }\end{array}$ \\
\hline \multirow[t]{2}{*}{2} & $\begin{array}{l}\text { - Discuss impact of potential } \\
\text { vulnerability factors (e.g., past } \\
\text { traumatic events) on FCR; }\end{array}$ & \multirow{2}{*}{$\begin{array}{l}\text { - Practice ATT on a daily basis } \\
\text { throughout the remainder of } \\
\text { the intervention and } \\
\text { document in diary. }\end{array}$} \\
\hline & $\begin{array}{l}\text { - Discuss rationale and } \\
\text { practice of the Attention } \\
\text { Training Technique (ATT), a } \\
\text { technique designed to help } \\
\text { patients reduce their } \\
\text { tendency to ruminate and } \\
\text { shift their attention more } \\
\text { flexibly when thoughts about } \\
\text { recurrence occur. }\end{array}$ & \\
\hline \multirow[t]{2}{*}{3} & \multirow{2}{*}{$\begin{array}{l}\text { - Introduce the practice of } \\
\text { Detached Mindfulness, } \\
\text { designed to enhance meta- } \\
\text { awareness of cognition and } \\
\text { the ability to become an } \\
\text { objective observer of the } \\
\text { content of thoughts without } \\
\text { the need for evaluation or } \\
\text { reaction. }\end{array}$} & $\begin{array}{l}\text { - Continue daily practice } \\
\text { of ATT; }\end{array}$ \\
\hline & & $\begin{array}{l}\text { - Practice application of } \\
\text { detached mindfulness on } \\
\text { response to thoughts which } \\
\text { trigger FCR. }\end{array}$ \\
\hline \multirow[t]{8}{*}{4} & $\begin{array}{l}\text { - Provide information about } \\
\text { possible symptoms of } \\
\text { recurrence of breast or } \\
\text { colorectal cancer; }\end{array}$ & $\begin{array}{l}\text { - Continue daily practice of } \\
\text { ATT; }\end{array}$ \\
\hline & $\begin{array}{l}\text { - Provide guidelines to help } \\
\text { clients distinguish those from } \\
\text { benign physical complaints; }\end{array}$ & \multirow[t]{2}{*}{$\begin{array}{l}\text { - Practice detached } \\
\text { mindfulness in response to } \\
\text { emerging thoughts about FC; }\end{array}$} \\
\hline & $\begin{array}{l}\text { - Reassess self-examination } \\
\text { practices and medical } \\
\text { surveillance; }\end{array}$ & \\
\hline & $\begin{array}{l}\text { - Identify avoidant or } \\
\text { excessive behaviours; }\end{array}$ & \multirow{2}{*}{$\begin{array}{l}\text { - Devise an appropriate plan } \\
\text { based on best available } \\
\text { evidence about how to } \\
\text { respond to new symptoms; }\end{array}$} \\
\hline & $\begin{array}{l}\text { - Develop a behavioural } \\
\text { contract to help clients to } \\
\text { engage in recommended } \\
\text { levels of self-examination and } \\
\text { follow-up tests (if needed); }\end{array}$ & \\
\hline & $\begin{array}{l}\text { - Discuss beliefs that underpin } \\
\text { FCR (eg. beliefs about the } \\
\text { benefits of FCR, or beliefs } \\
\text { about physical harm caused } \\
\text { by FCR); }\end{array}$ & \multirow[t]{3}{*}{$\begin{array}{l}\text { - Practice worry } \\
\text { postponement. }\end{array}$} \\
\hline & $\begin{array}{l}\text { - Test the validity of these } \\
\text { beliefs through Socratic } \\
\text { dialogue. }\end{array}$ & \\
\hline & $\begin{array}{l}\text { - Introduce worry } \\
\text { postponement as a technique } \\
\text { for responding to residual } \\
\text { worries }\end{array}$ & \\
\hline
\end{tabular}

Table 1 Detailed content for the conquer fear intervention (Continued)

- Review goal setting task;

- Consolidate skills learned throughout the program;

- Develop relapse prevention plan.

The key goals of this manualised intervention are to:

- teach strategies for controlling worry and excessive threat monitoring;

- modify underlying unhelpful beliefs about worry;

- develop appropriate monitoring and screening behaviours;

- encourage acceptance of the uncertainty brought about by a cancer diagnosis;

- clarify values and encourage engagement in valuesbased goal setting.

The intervention is delivered in $5 \times 60-90$ minute, individual face-to-face sessions by a trained therapist over a period of 10 weeks (sessions are weekly/fortnightly). Each session is accompanied by home-based practice of skills learned in session and home reading to consolidate skill acquisition. See Table 1.

\section{Relaxation training}

Participants randomised to the control treatment receive a 5session relaxation training program over a period of 10 weeks, as detailed in Table 2. Participants receive training in progressive and passive muscle relaxation, meditative relaxation, visualisation and "quick relaxation" techniques, with regular home-based practice and a CD for practice outside sessions. The aim of the control condition is to provide an equivalent amount of therapist contact to Conquer Fear, to control for non-specific therapeutic factors (e.g. therapeutic alliance and support), in a treatment package with face validity so that patients are not aware they are in the control condition. Relaxation therapy may have some beneficial effects itself.

\section{Intervention fidelity checks}

Fidelity to treatment protocols in both arms will be ensured by: a) having therapists submit a completed checklist following each session; b) regular review of submitted session checklists; c) therapist participation in monthly group supervision; and d) recording of therapy sessions. A random selection of $10 \%$ of recordings will be assessed by the research team using a modified version of the revised cognitive therapy scale (CTS-R; [44]). The scale was designed to assess therapist competency in cognitive therapy, and has good psychometric properties [44]. The scale assesses skills specific to cognitive therapy, general therapeutic skills including therapeutic alliance and has 


\begin{tabular}{|c|c|c|}
\hline Session & Content & Home based practice \\
\hline \multirow[t]{4}{*}{1} & - Assess FCR; & \multirow{4}{*}{$\begin{array}{l}\text { Practice active PMR daily } \\
\text { for } 25 \text { minutes }\end{array}$} \\
\hline & $\begin{array}{l}\text { - Explain concept of stress, how it } \\
\text { can be adaptive when it becomes } \\
\text { a problem and how it can be } \\
\text { managed through relaxation; }\end{array}$ & \\
\hline & $\begin{array}{l}\text { - Introduce different stress } \\
\text { management techniques; }\end{array}$ & \\
\hline & $\begin{array}{l}\text { - Practice active progressive } \\
\text { muscle relation (PMR); }\end{array}$ & \\
\hline \multirow[t]{4}{*}{2} & $\begin{array}{l}\text { - Review active PMR and its } \\
\text { impact on stress levels; }\end{array}$ & \multirow[t]{4}{*}{$\begin{array}{l}\text { Practice passive PMR daily } \\
\text { for } 25 \text { minutes }\end{array}$} \\
\hline & $\begin{array}{l}\text { - Identify and resolve issues of } \\
\text { practicing active PMR; }\end{array}$ & \\
\hline & - Introduce passive PMR; & \\
\hline & - Practice passive PMR; & \\
\hline \multirow[t]{4}{*}{3} & $\begin{array}{l}\text { - Review passive PMR and its } \\
\text { impact on stress levels; }\end{array}$ & \multirow{4}{*}{$\begin{array}{l}\text { Incorporate meditative } \\
\text { relaxation into passive } \\
\text { PMR practice for } \\
25 \text { minutes daily }\end{array}$} \\
\hline & $\begin{array}{l}\text { - Identify and resolve issues } \\
\text { of practicing passive PMR; }\end{array}$ & \\
\hline & - Introduce meditative relaxation; & \\
\hline & - Practice meditative relaxation. & \\
\hline \multirow[t]{4}{*}{4} & $\begin{array}{l}\text { - Review meditative relaxation and } \\
\text { its impact on stress levels; }\end{array}$ & \multirow{10}{*}{$\begin{array}{l}\text { Incorporate visualisation } \\
\text { into passive PMR practice } \\
\text { for } 25 \text { minutes daily }\end{array}$} \\
\hline & $\begin{array}{l}\text { - Identify and resolve issues } \\
\text { of practicing meditative relaxation; }\end{array}$ & \\
\hline & $\begin{array}{l}\text { - Introduce visualisation as a way } \\
\text { of shortcutting the stress } \\
\text { response; }\end{array}$ & \\
\hline & - Practice visualisation. & \\
\hline \multirow[t]{6}{*}{5} & $\begin{array}{l}\text { - Review visualisation and its } \\
\text { impact on stress levels; }\end{array}$ & \\
\hline & $\begin{array}{l}\text { - Identify and resolve issues } \\
\text { of practicing visualisation; }\end{array}$ & \\
\hline & $\begin{array}{l}\text { - Introduce quick relaxation } \\
\text { techniques; }\end{array}$ & \\
\hline & - Practice quick relaxation; & \\
\hline & $\begin{array}{l}\text { - Review skills learnt and } \\
\text { progress made; }\end{array}$ & \\
\hline & $\begin{array}{l}\text { - Develop plan for future practice } \\
\text { of relaxation techniques. }\end{array}$ & \\
\hline
\end{tabular}

been modified to include competency in skills necessary for the FCR intervention that are not otherwise covered by the CTS-R. Feedback will be given where non-fidelity is identified, as recommended by the validated 'Method of Assessing Treatment Delivery' [45].

\section{Pilot study}

A pilot study of the intervention was carried out between October 2010 and December 2011 [22]. Results are presented in detail elsewhere [22]. In brief, ten psychologists / psychiatrists took part in a 1-day training session held in October 2010. In post-training questionnaires, all therapists had increased knowledge about and confidence in managing FCR. At the close of the pilot 4 therapists had recruited 8 participants (2 each). Recruitment was $83 \%$ and retention rates $100 \%$. Both patients and therapists were highly satisfied with the intervention. Patients reported finding the intervention very helpful and had a significant and clinically meaningful reduction in FCR as measured by the FCRI.

\section{Outcomes}

All participant outcomes are assessed using either an online or paper and pencil self-report questionnaire containing the measures listed below. Participants are posted or emailed, as preferred, the questionnaires, to be completed and returned in a reply-paid envelope or online. Questionnaires are completed upon enrollment in the study prior to randomisation, immediately after treatment completion, 3 and 6 months after treatment completion. The researchers follow up participants who do not return their questionnaire within two weeks, with up to three phone calls at different times of the day according to a pro forma. If phone contact cannot be made, email and text reminders are sent where possible. Finally, a replacement questionnaire is sent 3 weeks after the non-returned questionnaire.

\section{Primary outcome}

Fear of Cancer Recurrence is assessed using the 42-item FCRI [39], the most comprehensive multi-dimensional scale of FCR available, and suitable for patients with mixed cancer diagnoses. It has been found to be internally consistent (Chronbach's $\alpha=0.75$ to 0.91 across subscales) and stable over a two-week interval ( $\rho=0.58$ to 0.83 across subscales), and has a robust factor structure. The FCRI has convergent validity with other standardised measures of FCR ( $\rho=0.66$ to 0.77$)$ and discriminant validity with QOL amongst a large sample $(n=600)$ of Canadian cancer patients with mixed tumours [39]. Respondents rate the degree to which symptoms or issues affect them on a Likert scale ranging from 0 ('not at all' or 'never') to 4 ('a great deal' or 'all the time'). Higher scores indicate higher FCR.

\section{Secondary outcomes}

- Cancer-specific distress is assessed with the 22 item Impact of Event Scale [46] with two subscales: intrusion and avoidance.

- General distress is assessed with the Depression, Anxiety, Stress Scale, 21 item short form $[47,48]$.

- Quality of life is assessed with the AQoL8D, a 35 item health-related QOL instrument that includes domains of mental health, coping, self-worth, happiness, relationships, along with the other 
subscales assessing functional aspects of QOL; independent living, pain, and senses. The AQoL8D $[49,50]$ also allows the calculation of qualityadjusted-life years (QALYs) through the health state utility scoring algorithm.

- Unmet needs are assessed using the 8 item Information sub-scale of the Survivors Unmet Needs Survey, which includes needs relating to finding information, knowing which information to trust and worrying about cancer recurrence and spread [51].

- Treatment satisfaction is evaluated using a single question assessing overall satisfaction with the therapy.

\section{Exploratory outcomes}

- Metacognitions (the cognitive processes, strategies, and knowledge that are involved in the regulation and appraisal of thinking itself.'[52]) are measured with the Metacognitions Questionnaire-30 [52,53], a 30 item questionnaire with 5 subscales measuring: cognitive confidence; positive beliefs about worry; cognitive self-consciousness; uncontrollability and danger; and need to control thoughts.

- Fear of cancer recurrence will also be measured using the Concerns About Recurrence Questionnaire (CAR-Q), a 5 item purpose designed questionnaire developed by $\mathrm{BT}$ and $\mathrm{PB}$, to act as a brief screen of FCR. This is to test the psychometric properties of the CAR-Q.

\section{Potential covariates}

Clinical and demographic information will include age, time since diagnosis, marital status, education, parity, stage of disease, treatment received (both medical and psychological) and current treatment (e.g. anti-depressants (if any)). In addition individual level of perceived risk of cancer recurrence will be assessed as this may influence firstly level of FCR prior to treatment and also treatment efficacy. Other potential covariates related to treatment are therapeutic alliance and treatment expectancy and credibility. Therapeutic alliance, which has consistently been shown to be associated with treatment outcome [54], will be assessed using the 12-item Working Alliance Inventory short-form revised (WAI-SR) [55]. The WAI-SR assesses the agreement on goal, the agreement on tasks that achieve the goal, and bond between patient and therapist. Treatment expectancy, which has been shown to predict treatment outcomes in a variety of contexts [56], will be measured using the 6item Credibility/Expectancy Questionnaire [57].

\section{Therapist measures}

Training evaluation is completed by participating therapists immediately after training completion. The evaluation survey includes items surveying: basic demographic features, professional qualifications and experience, confidence in dealing with FCR pre- and post-training, and satisfaction with the intervention training content and delivery using purpose designed Likert scales. This survey was used in our previous pilot study [22].

\section{Economic measures and analysis}

Economic evaluation will be a cost-consequences analysis conducted from both the broad societal perspective and the narrower perspective of the health care sector. The economic evaluation will compare any incremental costs of the intervention (costs accrued in the intervention arm compared to costs accrued in the control arm) to the full list of incremental outcomes (including QALYs in a cost-utility analysis). The intervention costs in the evaluation will include only the costs of intervention delivery, (excluding development or research costs), to estimate the resource use required if the intervention was rolled-out into practice across Australia. The research team and provider records will be used to determine the costs of the intervention (screening costs, cost of intervention delivery and intervention materials).

Other costs associated with each arm of the trial will be estimated using a resource use diary. The diary will be used to document and measure health behaviours and service use - such as hospitalisation, other allied health consultations, use of alternative therapies and self-monitoring behaviours. The diary will also document days out-of-role (including paid and unpaid work) travel costs and carer costs. The diary will be based on existing resource use questionnaires used in national databases and will cover both costs paid for by the individual as well as those paid for by third parties (such as an insurance company). Measured resource use will be valued using existing unit costs from sources such as the Australian Refined Diagnosis Related Groups (AR-DRG). AR-DRG for costs of hospitalisation and Australian Bureau of Statistics estimates of Australian earnings for productivity effects. Based on previous research, questionnaires have been found to be reliable estimates of resource use [58].

Uncertainty in the cost and outcome data will be further evaluated through nonparametric bootstrap analysis. The sensitivity of economic evaluation results to the methods of evaluation will be tested through sensitivity analyses, whereby key evaluation parameters (such as unit costs), are varied to assess the impact on the study conclusions.

\section{Sample size}

This is a longitudinal randomised controlled trial, with one baseline measure and 3 post-intervention measures. 
The primary outcome is the Fear of Cancer Recurrence Inventory, a 42 item scale with a possible range of 168 .

We based our sample size calculation on $90 \%$ power, a two-sided $\alpha=0.05$ t-test, dropout of $30 \%$, a difference between groups of 14.5, and a standard deviation of 29 [39] (a standardised effect size of 0.5). The sample size calculations should account for the clustering of outcomes by therapist, and although there is no published intra-cluster correlation (ICC) for the FCRI, we took guidance from two large reviews on ICCs in similar contexts $[59,60]$ and used an ICC of 0.01. Assuming a total of 20 therapists, and following Donner and Klar, $[60,61]$ the required sample size is 13 patients per therapist, for a total of 260 patients. If dropout is lower, for example, $20 \%$ then this sample size allows for a larger intra-cluster correlation or a small detectable difference. This sample size also gives $90 \%$ power to detect a difference of $0.5 \mathrm{SD}$ between the groups in each of the secondary outcomes. The value includes attrition of $30 \%$, however, we expect attrition to be lower, since patients with FCR report a high level of need for help, and we experienced low attrition when piloting the intervention.

\section{Statistical analysis}

Analyses will be by intention-to-treat. Linear mixed models will be used to account for the hierarchical, nonindependent nature of the data: repeated measures on patients nested within therapist. A saturated time $\mathrm{x}$ treatment model with unstructured covariance structure will be used to guard against misspecification of the model. Random effects of patient and therapist will be used. The primary analysis will be the comparison at the each of the 3 post-baseline (post-treatment) time points of the two arms using a contrast within this mixed model. Overall pattern of change will be assessed by testing the treatment by time interaction. Adjusted analysis, including using baseline FCRI, sex, age, time since diagnosis, cancer type, perceived risk, treatment expectancy and therapeutic alliance will also be investigated. Variables will be included in the model if they have a Kendall's Tau correlation higher than 0.1 with FCRI. Mixed models yield unbiased estimates for data which are missing completely at random and at random [62], however, if the amount of missing data for the primary outcome is greater than $20 \%$, sensitivity analyses will be performed by multiply imputing the missing data, and adding and subtracting clinically plausible amounts from the imputed values. These new datasets will be reanalysed, to see how conclusions change.

Secondary outcomes (QoL, distress, unmet information needs) will be analysed in a similar way to the primary outcome. Treatment satisfaction and therapist training evaluation will be described with descriptive statistics. To see if colorectal and breast cancer patients responded differently to the treatment, we will test the interaction cancer type $\mathrm{x}$ treatment $\mathrm{x}$ time. Predictors of FCR, distress and QoL at baseline will be explored using multiple linear regression. The relationship between Metacognition and FCR will examined using 1) regression to see if there is a relationship at baseline in the entire sample and then 2) using mediation techniques following the methods of Baron and Kenny [63] in the treatment group only, immediately post baseline (time 1). The CAR-Q will be compared with the FCRI using psychometric techniques.

\section{Discussion}

\section{Theoretical significance}

This RCT advances the field by representing the first controlled trial of a novel, evidence-based and theoreticallybased model of psychological support for cancer survivors with high FCR. Further, the inclusion of a health economic evaluation will strengthen the study further. Given the dearth of intervention research anchored in theoretical frameworks, this trial is an important next step in filling the gap in knowledge about how best to support this large and growing group. Extensive preliminary research and pilot work has demonstrated the likely success of this model.

\section{Clinical significance}

The Conquer Fear intervention aligns with emerging priorities in survivorship care in cancer which identify promotion of quality of life and maximizing well-being and optimal participation in social and occupational roles as central to care, rather than the traditional surveillancebased approach to follow-up which focuses on identification of new disease or late complications of cancer treatment. It is also in line with consumer priorities for survivorship research [64]. This intervention has the potential to reduce FCR and improve the QoL of patients, and reduce health care costs. The eventual goal of this study is to distribute an evidence-based, manualised, psychological intervention for FCR. Implementation of the Conquer Fear intervention will therefore help to eradicate barriers to appropriate psycho-social care for survivors, and has farreaching service and policy implications in terms of implementing 'best practice' recommendations for the ever-increasing numbers of cancer survivors.

\footnotetext{
Abbreviations

FCR: Fear of cancer recurrence; RCT: Randomised controlled trial; FCRI: Fear of cancer recurrence inventory; CAR-Q: Concerns About Recurrence Questionnaire; S-REF: Self-Regulation of Executive Function; ATT: Attentional training technique; PMR: Progressive muscle relation; CTS_R: Revised cognitive therapy scale; QALY: Quality-adjusted-life year; WAI-SR: Working Alliance Inventory short-form revised; AR-DRG: Australian Refined Diagnosis Related Groups; ICC: Intra-cluster correlation.
}

\section{Competing interests}

The authors declare that they have no competing interests. 


\section{Authors' contributions}

$P B, B T, J T, J G, J B, A G, L S, M B$ \& CM were responsible for the conception and initial study design. ABS, JEF and SS were responsible for refining the study design and will be responsible for co-ordinating the acquisition of study data. MB, and SS will be responsible for analysis of study data. All authors were involved in drafting the manuscript and have read and approved the final manuscript.

\section{Acknowledgements}

This project was co-funded by beyondblue, National Breast Cancer Foundation and Cancer Australia. None of these funding bodies were involved in the design of the study, nor is it expected that they will be involved in the collection, analysis and interpretation of data, in writing future manuscripts or deciding to submit manuscripts for publication. The authors would like to thank the members of the Conquer Fear Authorship Group who have agreed to participate in the study at Crown Princess Mary Cancer Centre (Jemma Gilchrist), Nepean Cancer Care Centre (Laura Kirsten), Royal Brisbane and Women's Hospital (Jane Turner, Maree Grier, Amanda Fairclough, Amanda Francis), Queensland Health (Donna Byrne), St George Cancer Care Centre (Jacqueline Lim, Christina Brock, Kathryn Taylor), Prince of Wales Hospital (Kerry Tiller), Central Coast Cancer Services (Sue McConaghey), Macarthur Cancer Therapy Centre (Mey Teoh), Austin Health (Jo du Buisson), Royal Perth Hospital (Paula Watt, Theresa Faulkner, Mary Scott), Flinders Medical Centre (Lisa Beatty), Ballarat Health Services (Sarah McKinnon), Concorde Hospital (Sue Butler), NSW Cancer Centre (Barbara Bennett) WA Psycho-Oncology Service (James Penhale).

\section{Author details}

'Psycho-Oncology Co-operative Research Group (PoCoG), School of Psychology, The University of Sydney, Sydney, NSW 2006, Australia. ${ }^{2}$ School of Medicine, University of Queensland, Herston, QLD 4029, Australia. ${ }^{3}$ Crown Princess Mary Cancer Centre, Westmead, NSW 2145, Australia. ${ }^{4}$ Royal Prince Alfred Hospital, Camperdown, NSW 2050, Australia. ${ }^{5}$ Ingham Institute for Applied Medical Research, South Western Sydney Clinical School, University of New South Wales, Liverpool, NSW 2170, Australia. ${ }^{6}$ School of Psychology, The University of Sydney, Sydney 2006NSW, Australia. ${ }^{7}$ Health Economics Unit, Deakin University, Burwood, VIC 3125, Australia.

Received: 13 March 2013 Accepted: 26 March 2013 Published: 23 April 2013

\section{References}

1. Australian Bureau of Statistics: National health survey: summary of results australia 2004-05. Canberra: Australian Bureau of Statistics; 2006.

2. Australian Institute of Health and Welfare: Cancer survival and prevalence in Australia; cancers diagnosed from 1982 to 2004. Canberra: AlHW; 2008.

3. Hewitt M, Greenfield S, Stovall E: From cancer patient to cancer survivor: lost in transition. Washington DC: Institute of Medicine (IOM); 2006.

4. Vickberg SMJ: The concerns about recurrence scale (CARS): A systematic measure of women's fears about the possibility of breast cancer recurrence. Ann Behav Med 2003, 25(1):16-24.

5. Armes J, Crowe M, Colbourne L, Morgan H, Murrells T, Oakley C, Palmer N, Ream $E$, Young A, Richardson A: Patients' supportive care needs beyond the end of cancer treatment: A prospective, longitudinal survey. J Clin Oncol 2009, 27(36):6172-6179.

6. Harrison SE, Watson EK, Ward AM, Khan NF, Turner D, Adams E, Forman D, Roche MF, Rose PW: Primary health and supportive care needs of long-term cancer survivors: A questionnaire survey. J Clin Oncol 2011, 29(15):2091-2098.

7. Sanson-Fisher R, Girgis A, Boyes A, Bonevski B, Burton L, Cook P: The unmet supportive care needs of patients with cancer. Supportive Care Review Group. Cancer 2000, 88(1):226-237.

8. Simard S, Savard J: Screening and psychiatric comorbidity of clinical fear of cancer recurrence. 4th Canadian Breast Cancer Research Alliance Reasons for Hope Scientific Conference: Vancouver, Canada; 2008

9. Thewes B, Butow P, Bell ML, Beith J, Stuart-Harris R, Grossi M, Capp A, Dalley $D$ : Fear of cancer recurrence in young women with a history of earlystage breast cancer: a cross-sectional study of prevalence and association with health behaviours. Support Care Canc 2012, 20(11):2651-2659.

10. Thewes B, Boyes A, Girgis A: Fear of cancer recurrence in the first year after diagnosis; Results of a registry based study. In Abstracts of the IPOS 12th World Congress of Internation Psycho-Oncology Society (IPOS), PsychoOncology, Volume 19. Quebec City, Quebec, Canada; 2010:235.
11. Humphris GM, Rogers S, McNally D, Lee-Jones C, Brown J, Vaughan D: Fear of recurrence and possible cases of anxiety and depression in orofacial cancer patients. Int J Oral Maxillofac Surg 2003, 32(5):486-491.

12. LLewellyn C, Weinman J, McGurk M, Humphris GM: Can we predict which head and neck cancer survivors develop fears of cancer recurrence? J Psychosom Res 2008, 65:525-532.

13. van den Beuken-van Everdingen MHJ, Peters ML, de Rijke JM, Schouten HC, van Kleef M, Patijn J: Concerns of former breast cancer patients about disease recurrence: a validation and prevalence study. Psychooncology 2008, 17(11):1137-1145.

14. Kornblith AB, Powell M, Regan MM, Bennett S, Krasner C, Moy B, Younger J, Goodman A, Berkowitz R, Winer E: Long-term psychosocial adjustment of older vs younger survivors of breast and endometrial cancer. Psychooncology 2007, 16(10):895-903.

15. Ghazali N, Cadwallader E, Lowe D, Humphris G, Ozakinci G, Rogers SN: Fear of recurrence among head and neck cancer survivors: Longitudinal trends. Psychooncology 2012. doi:10.1002/pon.3114.

16. Crist JV, Grunfeld EA: Factors reported to influence fear of recurrence in cancer patients: A systematic review. Psychooncology. In Press.

17. Koch $L$, Jansen $L$, Brenner $H$, Arndt V: Fear of recurrence and disease progression in long-term ( $>5$ years) cancer survivors-a systematic review of quantitative studies. Psychooncology 2012. doi:10.1002/pon.3022. In Press.

18. Skaali T, Fossa SD, Bremnes R, Dahl O, Klepp O, Wist E, Dahl AA: Fear of recurrence in long-term testicular cancer survivors. Psychooncology 2007, 16(9):P1-P172.

19. Hodges L, Humphris $G$ : Fear of recurrence and psychological distress in head and neck cancer patients and their carers. Psychooncology 2009, 18(8):841-848.

20. Mehta SS, Lubeck DP, Pasta DJ, Litwin MS: Fear of cancer recurrence in patients undergoing definitive treatment for prostate cancer: results from CaPSURE. J Urol 2003, 170(5):1931-1933.

21. Mellon S, Kershaw TS, Northouse LL, Freeman-Gibb L: A family-based model to predict fear of recurrence for cancer survivors and their caregivers. Psychooncology 2007, 16(3):214-223.

22. Thewes B, Bell M, Smith A, Fardell J, Turner J, Butow P: Conquer Fear: The development and pilot testing of a novel psychological treatment for fear of cancer recurrence. In Abstracts of the of IPOS 14th World Congress of PsychoOncology, Asia-Pacific Journal of Clinical Oncology, Volume 8. 2012:207.

23. Hart S, Latini D, Cowan J, Carroll P, CaPSURE Investigators: Fear of recurrence, treatment satisfaction, and quality of life after radical prostatectomy for prostate cancer. Supportive Cancer Care 2008, 16:161-169.

24. Glynne-Jones R, Chait I, Thomas F: When and how to discharge cancer curvivors in long term remission from follow-up: the effectiveness of a contract. Clin Oncol 1997, 1:25-29.

25. Maszczakiewicz E, Jolicoeur L, Lebel S, Lefevbre M, Bakker D: Fear of recurrence and its effects on patient satisfaction with follow-up after primary therapy for endometrial cancer. In Abstracts of the Annual Scientific Meeting of the Canadian Association of Psychosocial Oncology. Vancouver, Canada; 2009.

26. Burstein H, Gelber S, Guadognoli E, Weeks J: The use of alternative medicine by women with early-stage breast cancer. N Engl J Med 1999, 340(22):1733-1739.

27. Montazeri A, Sajadian A, Ebrahimi M, Haghighat S, Harirchi I: Factors predicting the use of complementary and alternative therapies among cancer patients in Iran. Eur J Canc Care 2007, 16(2):144-149.

28. Rakovitch E, Pignol J, Chartier C, Ezer M, Verma S, Dranitsaris G, Clemons M: Complementary and alternative medicine use is associated with an increased perception of breast cancer risk and death. Breast Canc Res Treat 2005, 90(2):139-148.

29. Humphris GM, Ozackinci G: The AFTER intervention: A structured psychological approach to reduce fears of recurrence in patients with head and neck cancer. Br J Health Psychol 2008, 13(2):223-230.

30. Easterling DV, Leventhal $\mathrm{H}$ : Contributions of concrete cognitionj to emotion: Neutral symptoms as elicitors of worry about cancer. J Appl Psychol 1989, 74(5):787-796.

31. Leventhal H, Nerenz DR, Steele DJ: Illness representations and coping with health threats. In Handbook of psychology and health: Social psychological apsects of health. Edited by Baum A, Taylor SE, Singer JE. Hillsdale: Lawrence Erlbaum Associates; 1984:219-252.

32. Mishel M, Germino B, Gil K, Belyea M, Laney I, Stewart J, Porter L, Clayton M: Benefits from an uncertainty management intervention for AfricanAmerican and Caucasian older long-term breast cancer survivors. Psychooncology 2005, 14(1):962-978. 
33. Sabariego C, Brach M, Herschbach P, Berg P, Stucki G: Cost-effectiveness of cognitive-behavioral group therapy for dysfunctional fear of progression in cancer patients. Eur J Health Econ 2011, 12(5):489-497.

34. Herschbach P, Book K, Dinkel A, Berg P, Waadt S, Duran G, Engst-Hastreiter $U$, Henrich G: Evaluation of two group therapies to reduce fear of progression in cancer patients. Support Care Canc 2010, 18(4):471-479.

35. Dinkel A, Herschbach P, Berg P, Waadt S, Duran G, Engst-Hastreiter U, Henrich G, Book K: Determinants of long-term response to group therapy for dysfunctional fear of progression in chronic diseases. Behav Med 2012, 38(1):1-5.

36. Lengacher $C$, Jonhson-Mallard V, Post-White J, Moscosco M, Jacobsen $P$, Klein T, Widen R, Fitzgerald S, Shelton M, Barta M, et al: Randomised controlled trial of mindfulness-based stress reduction (MBSR) for survivors of breast cancer. Psychooncology 2009, 18(12):1261-1272.

37. Kabat-Zinn J, Massion AO, Kristeller J, Peterson LG, Fletcher K, Pbert L, Linderking W, Santorelli SF: Effectiveness of a meditation-based stress reduction program in the treatment of anxiety disorders. Am J Psychiatr 1992, 149(7):936-943.

38. Cameron LD, Booth $R$, Schlatter M, Ziginskas D, Harman J: Changes in emotion regulation and psychological adjustment following use of a group psychosocial support program for women recently diagnosed with breast cancer. Psychooncology 2007, 16:171-180.

39. Simard S, Savard J: Fear of Cancer Recurrence Inventory: Development and initial validation of a multidimensional measure of fear of cancer recurrence. Support Care Canc 2009, 17(3):241-251.

40. Stein K, Kaw C, Spillers R: Prevalence and Correlates of Fear of Cancer Recurrence among Cancer Survivors. In Abstracts of the IPOS 12th World Congress of Psycho-Oncology, Psycho-Oncology, Volume 19. 2012:17.

41. Wells A: Metacognitive therapy: cognition applied to regulating cognition. Behav Cogn Psychother 2008, 36(Special Issue 06):651-658.

42. Wells A, Matthews G: Modelling cognition in emotional disorder: The SREF model. Behav Res Ther 1996, 34(11-12):881-888.

43. Hayes S, Strohsahl K, Wilson K: Acceptance and commitment therapy; an experiential approach to behaviour change. New York: Guildford Press; 2003.

44. Blackburn IM, James IA, Milne DL, Baker C, Standart S, Garland A, Reichelt FK: The revised cognitive therapy scale (CTS-R): Psychometric properties. Behav Cogn Psychother 2001, 29(4):431-446.

45. Leeuw M, Goossens M, de Vet H, Vlaeyen J: The fidelity of treatment delivery can be assessed in treatment outcome studies: a successful illustration from behavioral medicine. J Clin Epidemio/ 2009, 62:81-90.

46. Horowitz MJ, Wilner N, Alvarez W: Impact of event scale: a measure of subjective stress. Psychosom Med 1979, 41:209-218.

47. Antony MM, Cox BJ, Enns MW, Bieling PJ, Swinson RP: Psychometric properties of the 42-item and 21-item versions of the Depression Anxiety Stress Scales in clinical groups and a community sample. Psychol Assess 1998, 10(2):176-181.

48. Henry JD, Crawford JR: The short-form version of the depression anxiety stress scales (DASS-21): construct validity and normative data in a large non-clinical sample. Br J Clin Psychol 2005, 44(2):227-239.

49. Richardson J, lezzi A, Khan M, Sinha K, Mihalopoulos C, Herrman H, Hawthorne G, Schweitzer I: Data used in the development of the AQOL-8D (PsyQoL) quality of life instrument. Research paper 40. Melbourne: Centre for Health Economics, Monash University; 2009.

50. Richardson J, Khan M, lezzi A: Preliminary results for the validation of the assessment of quality of life AQOL-8D instrument. Research paper 47. Melbourne: Centre for Health Economics, Monash University; 2010.

51. Campbell HS, Sanson-Fisher R, Turner D, Hayward L, Wang XS, Taylor-Brown $\mathrm{J}$ : Psychometric properties of cancer survivors' unmet needs survey. Support Care Canc 2010, 19(2):221-230.

52. Wells A, Cartwright-Hatton S: A short form of the metacognitions questionnaire: properties of the MCQ-30. Behav Res Ther 2004, 42(4):385-396

53. Spada MM, Mohiyeddini C, Wells A: Measuring metacognitions associated with emotional distress: Factor structure and predictive validity of the metacognitions questionnaire 30. Personal Individ Differ 2008, 45(3):238-242.

54. Martin DJ, Garske JP, Davis MK: Relation of the therapeutic alliance with outcome and other variables: a meta-analytic review. J Consult Clin Psychol 2000, 68(3):438-450.

55. Hatcher RL, Gillaspy JA: Development and validation of a revised short version of the working alliance inventory. Psychother Res 2006, 16(1):12-25.

56. Smeets RJEM, Beelen S, Goossens MEJB, Schouten EGW, Knottnerus JA, Vlaeyen JWS: Treatment expectancy and credibility Are associated with the outcome of both physical and cognitive-behavioral treatment in chronic Low back pain. Clin J Pain 2008, 24(4):305-315. doi:310.1097/ AJP.1090b1013e318164aa318175.

57. Devilly GJ, Borkovec TD: Psychometric properties of the credibility/ expectancy questionnaire. J Behav Ther Exp Psychiatr 2000, 31(2):73-86.

58. Mandelblatt JS, Cullen J, Lawrence WF, et al: Economic evaluation alongside a clinical trial of psycho-educational interventions to improve adjustment to survivorship among patients with breast cancer. J Clin Oncol 2008, 26:1684-1690.

59. Adams G, Gulliford MC, Ukoumunne OC, Eldridge S, Chinn S, Campbell MJ: Patterns of intra-cluster correlation from primary care research to inform study design and analysis. J Clin Epidemiol 2004, 57(8):785-794.

60. Bell ML, McKenzie JE: Designing psycho-oncology randomised trials and cluster randomised trials: variance components and intra-cluster correlation of commonly used psychosocial measures. Psychooncology 2012. doi:10.1002/pon.3205.

61. Donner A, Klar N: Design and analysis of cluster randomization trials in health research. London, UK: Arnold Publishing; 2000.

62. Fitzmaurice GM, Laird NM, Ware JH: Applied longitudinal analysis. 2nd edition. Hoboken NJ: Wiley; 2011.

63. Baron RM, Kenny DA: The moderator-mediator variable distinction in social psychological research. Conceptual, strategic, and statistical considerations. J Pers Soc Psychol 1986, 51(6):1173-1182.

64. Research priorities in breast cancer survivorship: what do breast cancer survivors think?. http://www.pc4tg.com.au/IMG/pdf/Marven.pdf.

doi:10.1186/1471-2407-13-201

Cite this article as: Butow et al:: Conquer fear: protocol of a randomised controlled trial of a psychological intervention to reduce fear of cancer recurrence. BMC Cancer 2013 13:201.

\section{Submit your next manuscript to BioMed Central and take full advantage of:}

- Convenient online submission

- Thorough peer review

- No space constraints or color figure charges

- Immediate publication on acceptance

- Inclusion in PubMed, CAS, Scopus and Google Scholar

- Research which is freely available for redistribution

Submit your manuscript at www.biomedcentral.com/submit
C) Biomed Central 